\title{
A New Method to Monitor the Coal Mining Subsidence by Gravimetry
}

\author{
Jinyun Guo ${ }^{*}, 1,2$, Hongjuan $\mathrm{Yu}^{1}$, Yi Shen ${ }^{1}$, Wang $\mathrm{Li}^{1}$ and Bin Guo ${ }^{1,2}$ \\ ${ }^{1}$ College of Geodesy and Geomatics, Shandong University of Science and Technology, Qingdao, 266590, P.R. China \\ ${ }^{2}$ State Key Laboratory of Mining Disaster Prevention and Control Co-founded by Shandong Province and Ministry of \\ Science \& Technology, Shandong University of Science and Technology, Qingdao, 266590, P.R. China
}

\begin{abstract}
Coal mining subsidence seriously affects the mine natural and ecological environment. Leveling is the traditional method to monitor the coal mining subsidence. It is possible to monitor the subsidence by gravimetry instead of leveling based on the negative linear correlation between the gravity change and the height change. Equations are derived to monitor the subsidence by gravimetry in the paper. Height change errors are analyzed by considering the uncertainties of gravity data and coal masses based on the error propagation theory. The probability integration method is utilized to simulate data of gravity, height and coal mass as well as the corresponding random errors. These data are processed with the new method to monitor the subsidence and its precision. The experimental results show that gravimetry can replace leveling to monitor the coal mining subsidence when the precision of gravity data is up to level of $3 \mu \mathrm{Gal}$.
\end{abstract}

Keywords: Gravimetry, mining subsidence, subsidence inversion, vertical gradient of gravity.

\section{INTRODUCTION}

Surface subsidence caused by the coal mining has a serious impact on the mine ecological environment and people's production and living. The subsidence should be forecasted and monitored in the mining design and the coal mining to further study the dynamic movement and deformation law [1]. Underground coal mining will cause the surface subsidence to form a surface subsidence basin. Traditionally, the typical method of monitoring land subsidence is the precise leveling [2]. Satellite-based techniques such as GPS and interferometric synthetic aperture radar (InSAR) are increasingly popular to monitor the coal mining subsidence. Height changes can be efficiently determined by GPS technique which will take the long time to collect GPS data and use the dedicated models to remove the environmental effects to achieve the observation precision of millimeter level [3-6]. InSAR can monitor the two-dimensional surface deformation with the limited spatial-temporal resolution. But its precision is often degraded due to the spatial decorrelation of SAR images, terrain effect and atmospheric effect [7,8]. It will take the long time and the workload to precisely monitor the mining subsidence with the precise leveling. Meantime the underground coal mining activity and progress cannot be reflected with the traditional method.

Gravimetry can be made to measure the regional gravity anomaly data to obtain the regional gravity change which can show the underground mass migration and the surface height change within the scope of coal mining influence. So the gravimetry can simultaneously get the underground mass change and surface height variation. The gravimetry is more efficient than the precise leveling [9-11]. Now the observation precision of absolute gravimeter can be up to level of $0.2-0.3 \mu \mathrm{Gal}[12,13]$, and the relative gravimeter can reach the precision of $\mu$ Gal- level $[14,15]$.

The gravity change on monitoring station is mainly resulted from the surface subsidence and the coal mass reduction caused by the underground coal mining. In general, the gravity change is linearly proportional to the height change $[14,16,17]$. The vertical gradient of free air gravity is used to transform the gravity change to the height change [18]. Based on the Newtonian law of universal gravitation, the gravity change caused by the mass balance is proportional to the mass reduction and inversely proportional to the distance square.

A new method to monitor the subsidence caused by the coal mining is put forward by gravimetry instead of precise leveling based on the physical geodesy in the paper. The simulation study based on the possibility integration method is made to verify the precision and feasibility of the new method.

\section{SUBSIDENCE MONITORING BY GRAVIMETRY}

\subsection{Basic Principle}

The coal mining activity can cause the underground mass reduction over the mining area. The mass reduction and the surface height change are combined to result in the gravity changes on monitoring stations by gravimetry. According to the theory of physical geodesy $[19,20]$, the gravity change is proportional to the elevation change without the mass change. The gravity change reflects the underground mass migration without the subsidence, and should be proportional to mass change and inversely proportional to the square of the distance. 
There is one monitoring station A (x,y) whose elevation settlement is $\Delta H$. Here $\Delta H$ is positive downward. The mining coal mass is $M_{0}$. So the gravity change $\Delta g$ on point A is

$$
\begin{aligned}
& \Delta g=\Delta g_{H}-\Delta g_{m} \\
& =\operatorname{grad}(g) \Delta H-G \int_{0}^{L_{1}} \int_{0}^{L_{2}} \int_{0}^{T_{c}} \frac{\rho}{r^{2}} d v \\
& =\operatorname{grad}(g) \Delta H-\frac{G M_{0}}{R^{2}}
\end{aligned}
$$

where $\operatorname{grad}(\mathrm{g})$ is the vertical gradient of gravity, $G$ is the gravitational constant, $\rho$ is the coal density, and $R$ is the distance between the coal mass center and the monitoring point, namely:

$$
R=\sqrt{\left(x-x_{0}\right)^{2}+\left(y-y_{0}\right)^{2}+\left(z-z_{0}\right)^{2}}
$$

The mass of coal mining is:

$$
M_{0}=\int_{0}^{L_{1}} \int_{0}^{L_{2}} \int_{0}^{T_{c}} \rho d v=\rho \times L_{1} \times L_{2} \times T_{c}
$$

in which $L_{2}$ is the coal mining width, $L_{l}$ is the coal mining length, and $T_{c}$ is the minable thickness of coalbed. These three variables can be obtained by the working face or the mining progress.

Knowing the gravity change, the coal mass and the mining area, we can get the subsidence as

$$
\Delta H=\frac{1}{\operatorname{grad}(g)}\left(\Delta g+\frac{G M_{0}}{R^{2}}\right)
$$

\subsection{Error Analysis}

Errors are present in the gravity data and the coal masses. So the subsidence precision on the monitoring point is contaminated by these errors. $\Delta g$ and $M_{0}$ are independent in Equation (4), whose root mean square errors are $m_{\Delta g}$ and $\mathrm{m}_{\mathrm{M} 0}$, respectively. The total differential of Equation (4) is

$\Delta_{\Delta H}=\frac{1}{\operatorname{grad}(g)} \frac{\partial f}{\partial \Delta g} \Delta_{\Delta g}+\frac{1}{\operatorname{grad}(g)} \frac{G}{R^{2}} \frac{\partial f}{\partial M_{0}} \Delta_{M_{0}}$

Following the law of error propagation, we can get the root mean square error of subsidence monitored by gravimetry is

$$
m_{\Delta H}=\frac{1}{\operatorname{grad}(g)} \sqrt{\left(m_{\Delta g}^{2}+\frac{G^{2}}{R^{4}} m_{M_{0}}^{2}\right)}
$$

In practice, the tolerance of coal weighing error is less than $3 / 1000$. For the coal production of more than 800,000 tons, the mass error of 1000 tons can meet the tolerance requirements. When the root mean square errors of gravity data are set to $1,2,3,5,7$, and $10 \mu \mathrm{Gal}$ respectively, the theoretical root mean square errors of height settlements calculated from gravity changes and mass reductions are listed in Table 1. From Table 1, it can be seen that the precision of subsidence value is better than $10 \mathrm{~mm}$ which can satisfy the requirement of mine surveying specifications [21] when the precision of gravity monitoring reached 3 $\mu \mathrm{Gal}$.
Table 1. Theoretical subsidence errors.

\begin{tabular}{|c|c|c|c|c|c|c|}
\hline $\mathbf{m}_{\Delta \mathbf{g}}(\boldsymbol{\mu} \mathbf{G a l})$ & 1 & 2 & 3 & 5 & 7 & 10 \\
\hline $\mathbf{m}_{\mathbf{W}}(\mathbf{m m})$ & 3.2 & 6.4 & 9.7 & 16.2 & 22.7 & 32.4 \\
\hline
\end{tabular}

\section{SIMULATION STUDY}

\subsection{Simulation Case}

Here one simulation experiment is made to verify the new method due to the shortage of practical gravity data over coal mining area. One coal mining working face is 1000 meters long and 200 meters wide with the coal thickness of $3.67 \mathrm{~m}$. The coal mass in the working face is about 880,000 tons. The subsidence coefficient is $\mathrm{q}=0.62$, the horizontal movement coefficient is $b=0.41$, the tangent of major influence angle is $\tan \beta=1.84$, the translation distance of inflection point is $\mathrm{s}_{0}=12 \mathrm{~m}$, the propagation angle is $\theta=85^{\circ}$, the dip angle of coal seam is $\alpha=80^{\circ}$, the average depth $\mathrm{H}_{0}=448 \mathrm{~m}$, and the coal density is $\rho=1.2 \times 10^{3} \mathrm{~kg} / \mathrm{m}^{3}$.

According to the above rock movement parameters, 512 monitoring points were designed with grid of $50 \times 50$ meters. The predicted subsidence of each point is calculated from Equation (7). The mining coal mass can be computed based on the size of working face and the coal density, seeing Fig. (1). The gravity change data can be estimated from the predicted settlement and the coal mass with the normal vertical gravity gradient of $0.3086 \mu \mathrm{Gal} / \mathrm{mm}$ by Equation (1). Then the subsidence of each point can be obtained from the simulated gravity data and the coal mass by Equation (3). So these simulated data are referenced for the following study to verify the correction of the inversed values.

Here we build one local coordinate system whose origin is at the lower-left corner of mining area, $x$-axis points to the strike, and $y$-axis points to the dip of the coalbed, seeing in Fig. (2). The monitoring point is $\mathrm{A}(\mathrm{x}, \mathrm{y})$ whose subsidence can be predicted by [22]

$$
\begin{aligned}
& w(x, y)=w_{\max } \times \frac{1}{2}\left\{\begin{array}{l}
{[\operatorname{erf}(\sqrt{\pi} \times(x / r))+1]-} \\
{\left[\operatorname{erf}\left(\sqrt{\pi} \times\left(\left(x-l_{1}\right) / r\right)\right)+1\right]}
\end{array}\right\} \\
& \times \frac{1}{2}\left\{\begin{array}{l}
{[\operatorname{erf}(\sqrt{\pi} \times(y / r))+1]-} \\
{\left[\operatorname{erf}\left(\sqrt{\pi} \times\left(\left(y-l_{2}\right) / r\right)\right)+1\right.}
\end{array}\right\} \\
& =w_{\max } c_{x} c_{y}
\end{aligned}
$$

where, $w_{\max }$ is the maximum subsidence value under the condition of fully mining, $c_{x}$ and $c_{y}$ are the subsidence distribution coefficients of point $\mathrm{A}(\mathrm{x}, \mathrm{y})$ along the strike and dip, respectively.

\subsection{Inversed Subsidence and Precision Analysis}

We should consider the error effects of gravity data and coal mass on the subsidence. So the random error of 1000 tons is added to the weighing coal mass. The simulated gravity data are also added by the random errors of 1, 2, 3, 5, 


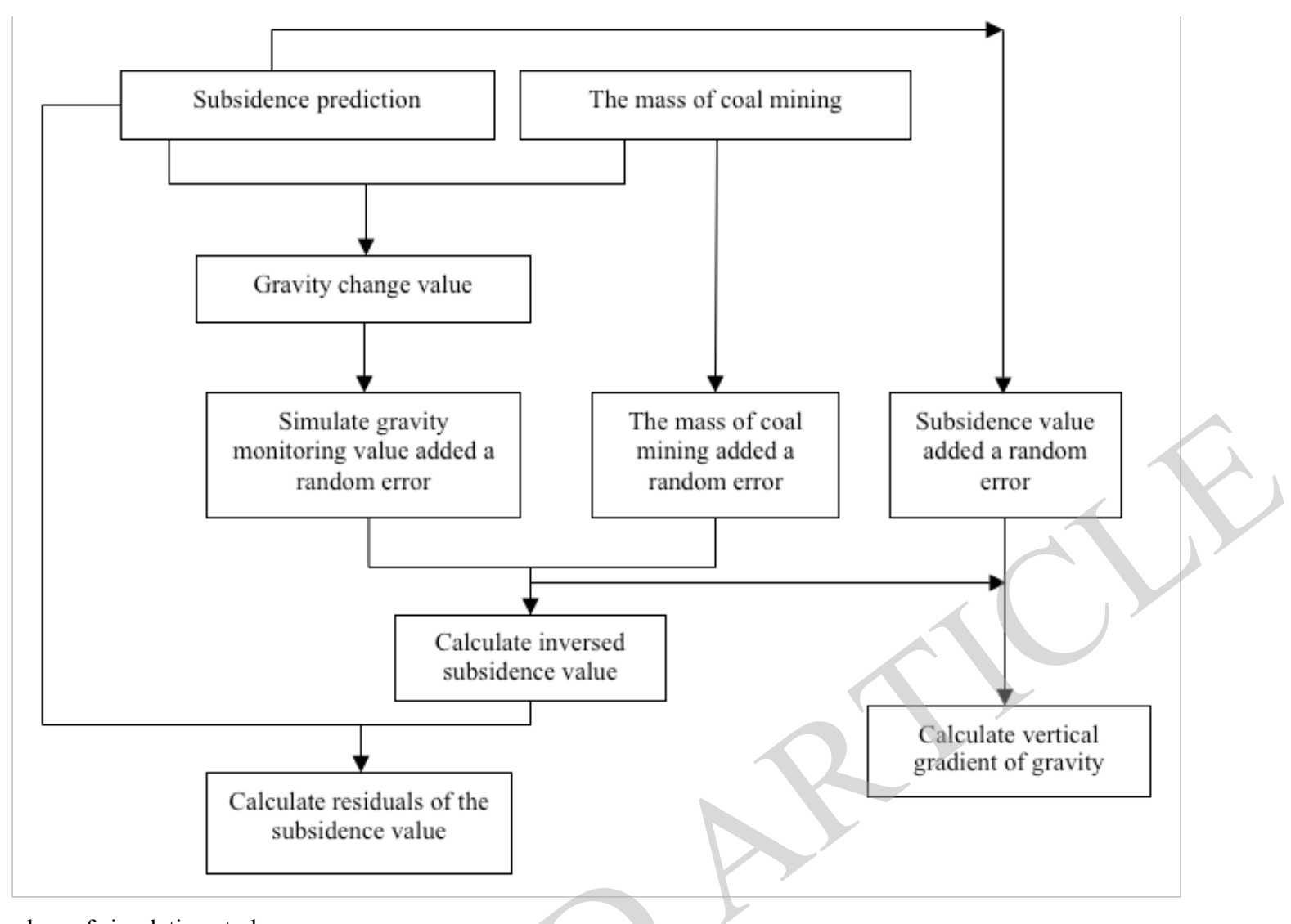

Fig. (1). Procedure of simulation study.

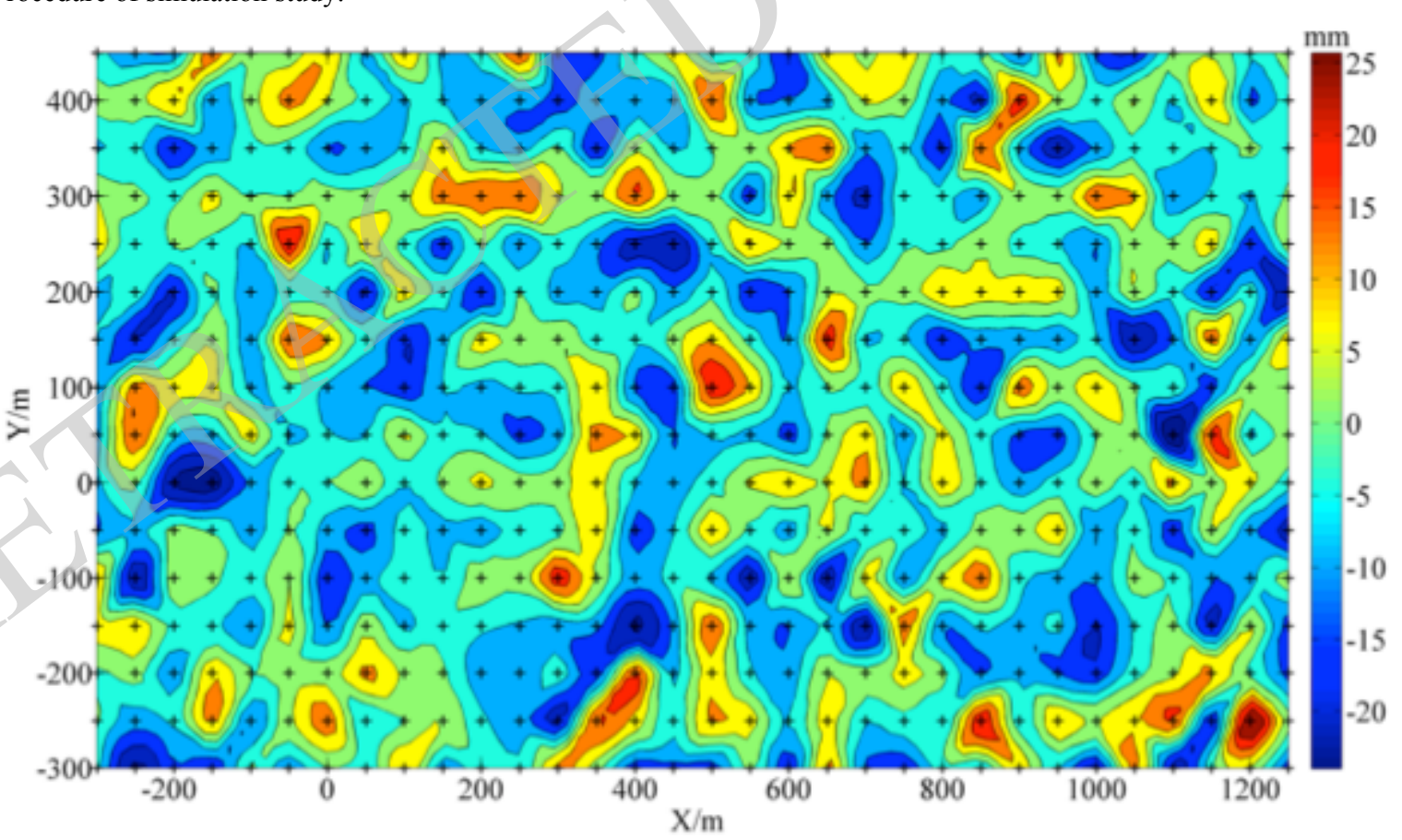

Fig. (2). Distribution of residuals between the inversed and the predicted height changes. Crosshairs represent grid points.

7, and $10 \mu$ Gals, respectively. Then the settlement of each point is inversed from these data including random errors. Differences between the inversed height changes and the predicted values from Equation (7) are calculated. The statistical results of these residuals are listed in Table 2.
These residuals when the random errors of $3 \mu \mathrm{Gals}$ are added to the gravity data are shown in Fig. (2).

The accidental error per kilometer for the fourth-order leveling is $5 \mathrm{~mm} .10 \mathrm{~mm}$ is considered the criterion to 
identify the boundary of the sinking basin [1]. So the precision threshold of subsidence is set up to $10 \mathrm{~mm}$. From Table 2 and Fig. (2), we can find that the precision of gravity data should be less than $3 \mu \mathrm{Gal}$ if the mining subsidence is monitored by the gravimetry technique. When the precision of gravity data is less than $2 \mu \mathrm{Gal}$, the precision of inversed subsidence can satisfy the requirement of the fourth-order leveling. From Tables $\mathbf{1}$ and $\mathbf{2}$, we can find that the theoretical precision is identical to the simulation study. So it is feasible to monitor the coal mining subsidence with the gravimetry.

Table 2. Statistic results of inversed subsidence values.

\begin{tabular}{|c|c|c|c|c|c|}
\hline $\begin{array}{c}\mathbf{m}_{\Delta \mathbf{g}} \\
\boldsymbol{\mu G a l}\end{array}$ & Maximum & Minimum & Mean & $\begin{array}{c}\text { Root } \\
\text { Mean } \\
\text { Square }\end{array}$ & $\begin{array}{c}\text { Standard } \\
\text { Deviation }\end{array}$ \\
\hline & \multicolumn{5}{|c|}{$\mathbf{m m}$} \\
\hline \hline 1 & 8.8 & -8.8 & 0 & 3.2 & 3.2 \\
\hline 2 & 17.7 & -17.2 & 0 & 6.5 & 6.5 \\
\hline 3 & 29.2 & -27.3 & 0 & 9.8 & 9.8 \\
\hline 5 & 52.9 & -47.3 & 0 & 17.3 & 17.3 \\
\hline 7 & 61.9 & -55.6 & 0 & 22.3 & 22.3 \\
\hline 10 & 93.6 & -82.4 & 0 & 31.6 & 31.6 \\
\hline
\end{tabular}

\subsection{Vertical Gradient of Gravity}

The vertical gradient of gravity seriously affects the precision of inversed subsidence with the method. It is very important to scientifically estimate the vertical gradient in the study. Here the normal vertical gradient is used in the simulation study. In practice, the vertical gradient should be computed from the real gravity changes, the height changes and the coal mass. These simulated data including random errors are used to estimate the vertical gradient to verify the effect of random error on the gradient by comparing the norm vertical gradient.

The large subsidence is commonly present in the central basin where the relatively high precision of gravity data and leveling data are also made. In the study 105 points in the central basin are selected to calculate the vertical gravity gradient. The coal mass has the random error of 1000 tons. The gravity data have the random errors of $1,2,3,5,7$, and $10 \mu \mathrm{Gal}$, respectively. The height data have the random errors of 3, 6, 10, 16,23 , and $32 \mathrm{~mm}$, respectively. Table 3 lists the statistical results of residuals between the normal vertical gradient and the inversed gradients. These residuals form the gravity data of 3 $\mu \mathrm{Gal}$ random errors and the height changes of $10 \mathrm{~mm}$ random errors are shown in Fig. (3). When the precision of gravity data is very high, the difference between the observed gradient and the normal value is only $0.001 \mu \mathrm{Gal} / \mathrm{mm}$. With the decreasing of the observation precision, the residual value increases.

Table 3. Statistic results of residuals between the observed and the normal vertical gravity gradient.

\begin{tabular}{|c|c|c|c|c|c|c|}
\hline \multirow{2}{*}{$\begin{array}{c}\mathbf{m}_{\mathbf{w}} \\
\mathbf{m m}\end{array}$} & \multirow{2}{*}{$\underset{\mu \mathrm{Gal}}{\mathbf{m}_{\Delta \mathrm{g}}}$} & Maximum & Minimum & Mean & Root Mean Square & Standard Deviation \\
\hline & & \multicolumn{5}{|c|}{$\mu \mathrm{Gal} / \mathrm{mm}$} \\
\hline 3 & 1 & 0.0040 & -0.0041 & 0.0001 & 0.0012 & 0.0012 \\
\hline 6 & 2 & 0.0047 & -0.0079 & 0.0001 & 0.0025 & 0.0025 \\
\hline 10 & 3 & 0.0100 & -0.0094 & 0.0004 & 0.0037 & 0.0037 \\
\hline 16 & 5 & 0.0172 & -0.0183 & 0.0005 & 0.0064 & 0.0064 \\
\hline 23 & 7 & 0.0287 & -0.0240 & 0.0006 & 0.0104 & 0.0103 \\
\hline 32 & 10 & 0.0367 & -0.0341 & -0.0012 & 0.0119 & 0.0118 \\
\hline
\end{tabular}

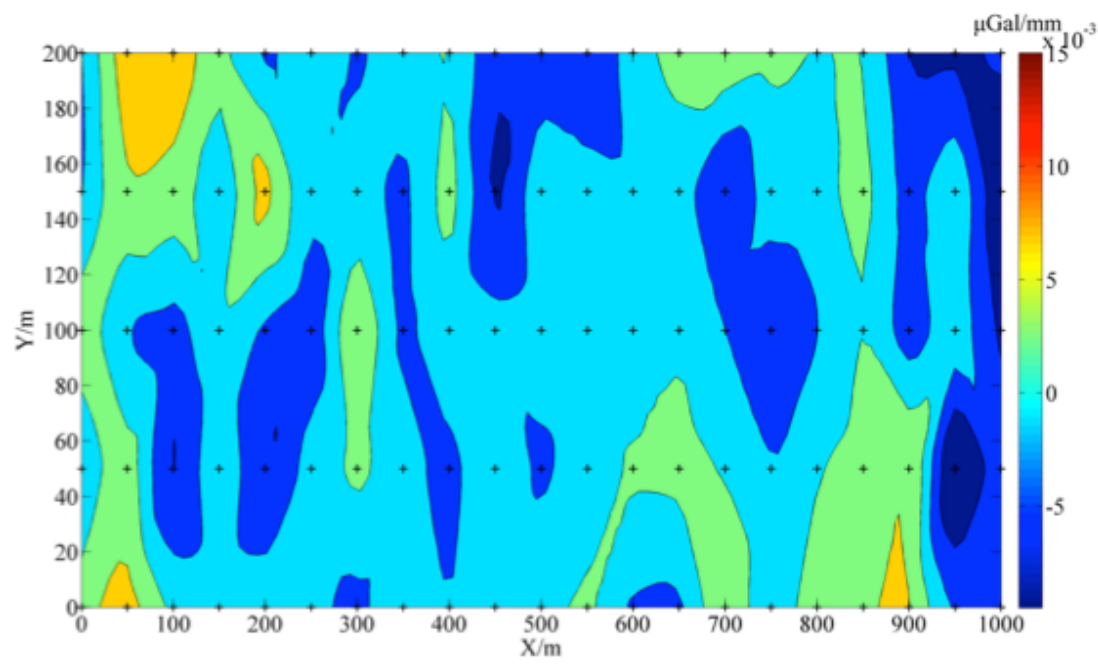

Fig. (3). Distribution of residuals between the observed and the normal vertical gravity gradient. 


\section{CONCLUSION}

Mining subsidence is one important factor to affect the natural and ecological environment in the coal mine and its neighborhood. Here we put forward one new method to monitor the subsidence of coal mining by the gravimetry technique. Gravity data can be used to inverse the settlements over the coal mining area with the high precision while knowing the mining coal mass. The real vertical gravity gradient can also be estimated from the gravity data and the height change data. The new method is of great significance to the mining research and the coal production. The experiment indicates that the new method can replace the leveling to monitor the surface subsidence.

\section{CONFLICT OF INTEREST}

The authors confirm that this article content has no conflict of interest.

\section{ACKNOWLEDGEMENTS}

This study is supported by the National Natural Science Foundation of China (41374009), The Public Benefit Scientific Research Project of China (201412001), The Shandong Natural Science Foundation of China (ZR2013DM009), and the SDUST Research Fund (2014TDJH101).

\section{REFERENCES} Subsidence Theory. Xuzhou: Press of China University of Mining and Technology, 1991, 166-194.

[2] Guo, J. Y.; Chang, X. T.; Yue, Q. Study on curved surface fitting model using GPS and leveling in coal area. Trans. Nonferrous Met. Soc. China, 2005, 15(2), 140-144.

[3] Dodson, A. H.; Shardlow, P. J.; Hubbard, L. C. M.; Elgered, G.; Jarlemark, P. O. J. Wet tropospheric effects on precise relative GPS height determination. J. Geodesy, 1996, 70(4), 188-202.

[4] Leick, A. GPS Satellite Surveying. Hoboken: John Wiley \& Sons, 2004, 182-206.

[5] Guo, J. Y.; Yuan, Y. D.; Kong, Q. L.; Li, G. W.; Wang, F. J. Deformation caused by 2011 eastern Japan great earthquake monitored by GPS singleepoch precise point positioning technique. Appl. Geophy., 2012, 9(4), 483-493.

[6] Guo, J. Y.; Li, G. W.; Kong, Q. L.; Wang, S. Y. Modeling GPS multipath effect based on spherical cap harmonic analysis. $T$. Nonferr. Metal. Soc., 2014, 24(6), 1874-1879.

[7] Massonet, D.; Feigl, K. L. Radar interferometry and its application to changes in the earth's surface. Rev. Geophys., 1998, 36(4), 441500 .

[8] Chang, X. T.; Guo, J. Y.; Zhang, Y. H.; Wang, X. Q. On the application of DInSAR to deformation monitoring in desert areas. Appl. Geophy., 2011, 8(1), 86-93.

[9] Torge, W. Gravimetry for monitoring vertical crustal movements: potential and problems. Tectonophysics, 1986, 130(1), 385-393.

[10] Torge, W. Gravimetry. Berlin: W. de Gruyter, 1989, 55-76.

[11] Lambert, A.; Courtier, N.; James, T. S. Long-term monitoring by absolute gravimetry: Tides to postglacial rebound. J. Geodyn., 2006, 41(1), 307-317.

[12] Okubo, S.; Yoshida, S.; Sato, T.; Tamura, Y.; Imanishi, Y. Verifying the precision of a new generation absolute gravimeter FG5-Comparison with superconducting gravimeters and detection of oceanic loading tide. Geophys. Res. Lett., 1997, 24(4), 489-492.

[13] Niebauer, T. M.; Sasagawa, G. S.; Faller, J. E.; Hilt, R.; Klopping, F. A new generation of absolute gravimeters. Metrologia, 1995, 32(3), 159-180.

[14] Cheng, T. C. The gravity change in Taiwan area: observation and analysis. PhD thesis, Hsinchu: National Chiao Tung University, Hsinchu, Taiwan, 2013, 13-22.

[15] Yu, H. J.; Guo, J. Y.; Li, J. L.; Mu, D. P.; Kong, Q. L. Zero drift and solid Earth tide extracted from relative gravimetric data with principal component analysis. Geod. Geodyn., 2015, 6(2), 114-124.

[16] Hwang, C.; Wang, C. G.; Lee, L. H. Adjustment of relative gravity measurements using weighted and datum-free constraints. Comput. Geosci-uk., 2002, 28(9), 1005-1015.

[17] Hwang, C.; Cheng, T. C.; Cheng, C. C.; Hung, W. C. Land subsidence using absolute and relative gravimetry: a case study in central Taiwan. Surv. Rev., 2010, 42(315), 27-39.

[18] Gounaris, A.; Arabelos, D. N.; Rossikopoulos, D. Local vertical crustal movements in the Mygdonian Basin-north Greece, resulting from gravity and GPS measurements. Surv. Rev., 2007, 39(304), 124-131.

[19] Heiskanen, W. A.; Moritz, H. Physical geodesy. B. Geod. (19461975), 1967, 86(1), 491-492.

[20] Guo, J. Y. Physical geodesy foundation. Wuhan: Press of Wuhan University of Surveying and Mapping Science and Technology, 1994, 222-251.

[21] State Coal Industry Bureau. Mining regulations of buildings, water, railway and main roadway pillar design and pressure coal. Beijing: Coal Industry Press, 2004, 5-15.

[22] Jiang, Y.; Axel, P.; Anton, S. The application of surface movement and mining damage. Germany: VGE Mining Industry Press, 2006 , 12-24. 